Original Article

\title{
FACILE AND SENSITIVE HPLC-UV METHOD FOR DETERMINATION OF NINTEDANIB IN RAT PLASMA
}

\author{
KOHEI TOGAMI, KENTA FUKUDA, KOTARO YAMAGUCHI, SUMIO CHONO, HITOSHI TADA \\ Division of Pharmaceutics, Hokkaido Pharmaceutical University School of Pharmacy, Sapporo, Hokkaido, Japan \\ Email: k-togami@hus.ac.jp
}

Received: 27 Feb 2018 Revised and Accepted: 08 May 2018

\section{ABSTRACT}

Objective: In this study, a facile and sensitive high-performance liquid chromatographic method for determination of nintedanib in rat plasma was developed and validated.

Methods: After plasma protein was precipitated by addition of acetonitrile, the supernatant underwent centrifugation. An aliquot was then injected into a high-performance liquid chromatographic system with a Mightysil RP-18 GP II ODS column $(250 \times 3.0 \mathrm{~mm}$, length by inner diameter, 5 - $\mu \mathrm{m}$ particle size) maintained at $50{ }^{\circ} \mathrm{C}$. A mobile phase mixture of $20 \mathrm{mmol}$ phosphate buffer (pH 3.0) and acetonitrile (7:3, v/v) was used at a flow rate of $0.6 \mathrm{~mL} / \mathrm{min}$, with UV detection at a wavelength of $390 \mathrm{~nm}$ for isocratic separation and detection of nintedanib, its main metabolite (BIBF1202), and $p$-nitrophenol as an internal standard.

Results: The quantitative range of nintedanib concentration in this method was $12.5-400 \mathrm{ng} / \mathrm{ml}$, and the calibration curves were linear. The intraand inter-day accuracy values (relative errors) were in the range of $-3.65 \%-4.00 \%$ and $-3.65 \%-3.64 \%$, respectively. The intra-and inter-day precision values (relative standard deviations) were $<5.9 \%$ and $8.36 \%$, respectively. The method was successfully applied to a pharmacokinetic analysis of nintedanib in rats after intravenous administration.

Conclusion: In this study, a rapid, sensitive, and simple HPLC-UV method for the quantitation of nintedanib in rat plasma was developed and validated. The method was shown to be accurate and precise and was successfully applied to a pharmacokinetic study.

Keywords: Nintedanib, BIBF1202, HPLC-UV, Idiopathic pulmonary fibrosis, Pharmacokinetic study

(C) 2018 The Authors. Published by Innovare Academic Sciences Pvt Ltd. This is an open access article under the CC BY license (http://creativecommons.org/licenses/by/4.0/) DOI: http://dx.doi.org/10.22159/ijpps.2018v10i6.25504

\section{INTRODUCTION}

Nintedanib, methyl (3Z)-3-[[4-[methyl-[2-(4-methyl piperazine-1yl)acetyl]amino]anilino]-phenylmethylidene]-2-oxo-1H-indole-6carboxylate, is a multiple tyrosine kinase inhibitor for plateletderived growth factor receptor (PDGFR), fibroblast growth factor receptor (FGFR), and vascular endothelial growth factor receptor (VEGFR) [1]. The drug has significant anti-fibrotic effects, including inhibition of proliferation, degradation of the extracellular matrix, and inhibition of collagen secretion [2]. Therefore, nintedanib is clinically used as an anti-fibrotic drug for the treatment of idiopathic pulmonary fibrosis (IPF) in the EU, USA, Japan, and Switzerland (OFEV®) $[3,4]$.

The pharmacokinetics of several tyrosine kinase inhibitors have indicated the likelihood that treatment outcomes for IPF would be affected, and clinical studies have reported a relationship between clinical outcomes and tyrosine kinase inhibitor concentrations in plasma $[5,6]$. The occurrence of adverse events, including diarrhea and nausea, of nintedanib are dose-dependent [7]. Thus, determination of nintedanib concentration in plasma is important in the treatment of IPF. In addition, since nintedanib is a substrate of multidrug resistance protein 1 (MDR1) [8], determination of intracellular concentrations of nintedanib in various cells that express the transporter is desirable.

Recently, analytical methods using ultra liquid chromatography with tandem mass spectrometry (UPLC-MS/MS) have been reported for the determination of nintedanib in biological samples [9]. However, UPLC-MS/MS cannot be used for routine analysis in each laboratory because of its high purchase cost, high maintenance cost, and running costs. On the other hand, a high-performance liquid chromatography with ultraviolet detection (HPLC-UV) is cost effective and commonly used $[10,11]$. HPLC-UV method for determination of nintedanib has also been developed [12], but the method has an insufficient quantitative limit of $2 \mu \mathrm{g} / \mathrm{ml}$ for nintedanib because of the method's short detection wavelength (210 $\mathrm{nm}$ ). In addition, since nintedanib is rapidly metabolized to its metabolite BIBF 1202 [13], it is necessary to verify the separability of nintedanib and BIBF 1202.

In the present study, we demonstrated a facile and sensitive HPLCUV method for measurement of nintedanib concentrations. In addition, the method was successfully applied to the pharmacokinetic analysis of nintedanib in rats after intravenous administration.

\section{MATERIALS AND METHODS}

Materials and animals

Nintedanib was purchased from Cayman Chemical Co., Ltd. (Ann Arbor, MI, USA), BIBF 1202 was purchased from Med Chem Express Inc. (Monmouth Junction, $\mathrm{NJ}, \mathrm{USA}$ ) and $p$-nitrophenol was purchased from Wako Pure Chemicals Co., Ltd. (Osaka, Japan). All other reagents were commercially available and of analytical grade. Male Sprague-Dawley rats, $5 \mathrm{w}$ old and weighing 160-180 g were purchased from Japan SLC (Shizuoka, Japan). The animal experimental protocol was approved by the Committee of the Laboratory Animal Center (No. H29-001) and confirmed to the Guiding Principles for the Care and Use of Experimental Animals at Hokkaido Pharmaceutical University.

\section{Determination of appropriate UV wavelength}

The appropriate wavelength for detection of nintedanib in the mobile phase described below was determined by using a UV-Vis spectrophotometer (UV-2550; Shimadzu, Kyoto, Japan) to scan the wavelengths over the range of $200-500 \mathrm{~nm}$.

\section{Apparatus and HPLC conditions}

The chromatographic system consisted of a Shimadzu model LC10ATVP pump, Shimadzu model SIL-10ADvp auto-injector, and 
Shimadzu model SPD-10Avp absorbance detector. A Mightysil RP-18 GPII column $(250 \times 3.0 \mathrm{~mm}$, length by an inner diameter, $5-\mu \mathrm{m}$ particle size, Kanto Chemical Co., Tokyo, Japan) was used for HPLC. The mobile phase was a mixture of $20 \mathrm{mmol}$ potassium phosphate buffer $(\mathrm{pH}$ 3.0)/acetonitrile (7:3). The isocratic separation was performed at a flow rate of $0.6 \mathrm{ml} / \mathrm{min}$ at $50{ }^{\circ} \mathrm{C}$, and the column was monitored by UV absorbance detection at a wavelength of $390 \mathrm{~nm}$. The sample injection volume was $20 \mu \mathrm{L}$, and the total run time was $14 \mathrm{~min}$. Chromatograms were integrated and processed by using an online computer and Chromato-Pro software version 4.0 (Run Time Co., Tokyo, Japan).

\section{Preparation of the standard and quality control solutions of} nintedanib

A stock standard solution $(1 \mathrm{mg} / \mathrm{ml})$ of nintedanib was prepared in methanol and diluted with ion-free water to prepare working solutions at concentrations of $0.25,0.5,1,2,4$, and $8 \mu \mathrm{g} / \mathrm{ml}$, respectively. Standard solutions $(12.5,25,50,100,200$, and 400 $\mathrm{ng} / \mathrm{ml}$ ) of nintedanib were prepared from the working solutions by dilution with ion-free water. Quality control solutions used in the validation were prepared in the same manner as the standard solutions by using blank plasma collected from rats without nintedanib administration. An internal standard solution was prepared by dissolving $p$-nitrophenol $(12 \mu \mathrm{g} / \mathrm{ml})$ in acetonitrile. All solutions were stored at $4{ }^{\circ} \mathrm{C}$ before use.

\section{Sample preparation}

Plasma $(80 \mu \mathrm{l})$ was mixed with the internal standard solution in acetonitrile $(80 \mu \mathrm{l})$, followed by vortex mixing for $30 \mathrm{~s}$. After mixing, the preparation was centrifuged at $10,000 \mathrm{~g}$ for $5 \mathrm{~min}$ at $4^{\circ} \mathrm{C}$. The supernatant was passed through a $0.22 \mu \mathrm{m}$ filter (Millex-GV, Millipore Co., Billerica, MA, USA), and the filtrate was injected into HPLC system.

\section{Pharmacokinetic experiments in rats}

Nintedanib dissolved in $0.1 \mathrm{M} \mathrm{HCl}$ was administered intravenously at a dose of $25 \mathrm{mg} / 0.5 \mathrm{ml} / \mathrm{kg}$. At each designated time point, the rats were anaesthetized by using intraperitoneal injections of sodium pentobarbital and butorphanol tartrate at doses of 50 and $5 \mathrm{mg} / \mathrm{kg}$, respectively, and blood was collected from the jugular vein. The samples were stored at $-30{ }^{\circ} \mathrm{C}$ before measuring the drug concentrations. The concentrations of nintedanib were measured in each sample by HPLC as described above.

\section{Pharmacokinetic analysis}

The pharmacokinetic analysis was performed by using the noncompartmental analytical method. The terminal elimination rate constant $(\beta)$ for the drug concentration-time curves after intravenous administrations were determined by linear regression of the data points from the terminal portion of the complete concentration-time plots. The area under the drug concentrationtime curve $(A U C)$ was calculated by using the logarithmic trapezoidal rule up to the last measured drug concentration $[C$ (last)] and extrapolated to infinity by addition of a correction term [ $C$ (last)]/ $\beta$. The area under the first moment curve (AUMC) to the last measured drug concentration was calculated by using the linear trapezoidal rule and the addition of the correction term after the last measured point to infinity $\{[C$ (last) $] \times[C$ (last) $] / \beta\}$. The terminal elimination half-life $\left(T_{1 / 2}\right)$ was calculated by using equation (1):

$$
\mathrm{T}_{1 / 2}=\frac{\ln 2}{\beta}(1)
$$

The total body clearance ( $\left.C L_{t o t}\right)$ was calculated by using equation (2):

$$
\mathrm{CL}_{\text {tot }}=\frac{\text { Dose }}{\mathrm{AUC}}(2)
$$

Where $F$ is the absolute bioavailability. The mean resident time (MRT) was calculated by using equation (3):

$$
\text { MRT }=\frac{\text { AUMC }}{\text { AUC }}(3)
$$

The volume of distribution space $\left(V_{d}\right)$ was calculated by using equation (4):

$$
\mathrm{Vd}=\mathrm{CL}_{\mathrm{tot}} \times \operatorname{MRT}(4)
$$

\section{RESULTS}

\section{Selection of analytical wavelength}

To determine the absorbance wavelength for UV detection of nintedanib, the UV spectrum of nintedanib was acquired, as shown in fig. 1. The maximum absorbance of nintedanib was found to occur at $390 \mathrm{~nm}$, which was selected for UV detection of nintedanib by HPLC.

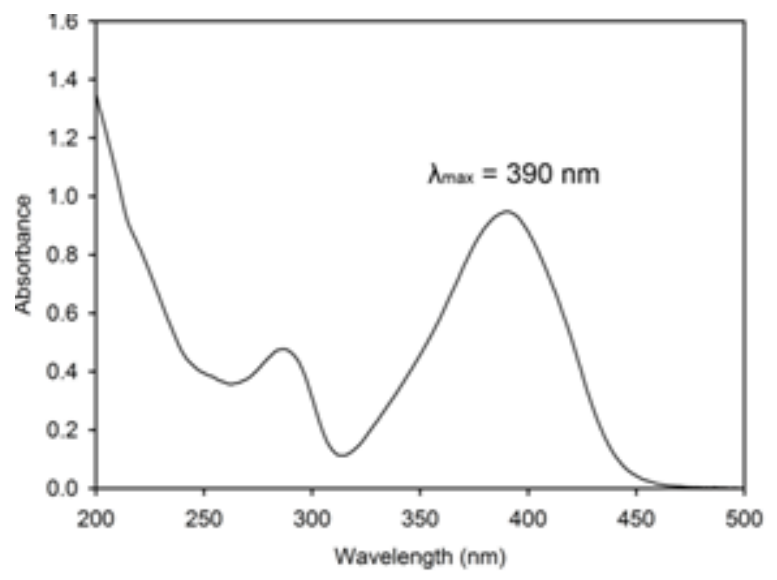

Fig. 1: UV spectrum of nintedanib $(10 \mu \mathrm{g} / \mathrm{ml})$ in the mobile phase for HPLC

\section{Specificity}

A typical elution pattern of nintedanib and its main metabolite (BIBF 1202) and internal standard (IS) in this method is shown in fig. 2. The peaks of nintedanib, BIBF 1202, and IS were completely separated (fig. 2A) and exhibited retention times of 12, 3.9, and 6.6 min, respectively. No interfering peaks were seen in the plasma blank (fig. 2B). At the same time, nintedanib, BIBF 1202, and IS were detected in the plasma after intravenous administration in rats (fig. 2C). In addition, to evaluate potential interference by the drugs listed in the IPF treatment guideline (12), including pirfenidone, prednisolone, bosentan, ambrisentan, macitentan, $N$-acetyl-Lcysteine, sildenafil, and warfarin, blank plasma samples spiked with these drugs were analyzed by HPLC. No interfering peaks were observed under the HPLC conditions fused for nintedanib determination (data not shown).

\section{Linearity}

Calibration curves were constructed from the relationship $(\mathrm{Y}=$ $\mathrm{aX}+\mathrm{b}$ ) between the peak area ratio $(\mathrm{Y})$ of nintedanib to IS versus nintedanib concentration (X). A least-squares linear analysis method was used to determine the slope, intercept, and correlation coefficient. Good linearity was indicated over the concentration range of 12.5 to $400 \mathrm{ng} / \mathrm{ml}$ for nintedanib $(r=0.9997)$. The regression curve was $\mathrm{Y}=0.00281 * \mathrm{X}+0.0024$. The limit of detection (signal-to-noise ratio $\geq 3$ ) for nintedanib was calculated to be 4 $\mathrm{ng} / \mathrm{ml}$.

\section{Accuracy, precision, and recovery}

The reproducibility of the analytical method for determination of nintedanib concentrations was evaluated by determining the intraand inter-day variances. The accuracy and precision data in this method are shown in table 1 . The intra-and inter-day accuracy values (relative error) were in the range of $-3.65 \%-4.00 \%$ and $-3.65 \%-3.64 \%$, respectively. The intra-and inter-day precision values (relative standard deviation) were $<5.95 \%$ and $8.36 \%$, respectively. The recovery for nintedanib from rat plasma was $>92 \%$. 
(A)

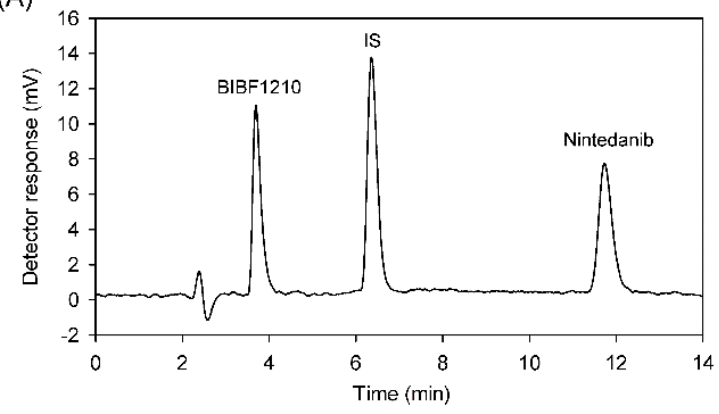

(B)

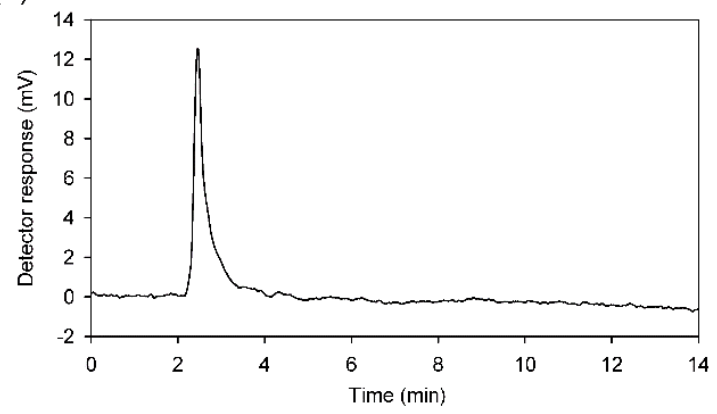

(C)

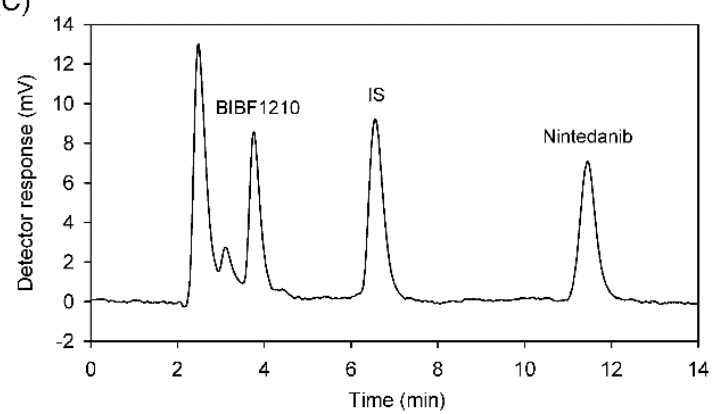

Fig. 2: Representative chromatograms of nintedanib. (A) nintedanib (400 ng/ml), its main metabolite (BIBF 1202, $400 \mathrm{ng} / \mathrm{ml})$, and internal standard (IS, $6 \mu \mathrm{g} / \mathrm{ml}$ ) dissolved in the mobile phase; (B) blank rat plasma; (C) real plasma samples of nintedanib in rats after 2-h intravenous administration of nintedanib $(20 \mathrm{mg} / \mathrm{kg} \mathrm{wt})$

Table 1: Intra-and inter-day validation of the analytical method of nintedanib in rat plasma

\begin{tabular}{|c|c|c|c|}
\hline \multirow{2}{*}{$\begin{array}{l}\text { Nominal concentration } \\
(\mathrm{ng} / \mathrm{ml})\end{array}$} & \multicolumn{3}{|l|}{ Intra-day } \\
\hline & Measured concentration $(\mathrm{ng} / \mathrm{ml})$ & Accuracy (RE \%) & Precision (RSD \%) \\
\hline 12.5 & $12.7 \pm 0.8$ & 1.36 & 5.95 \\
\hline 25 & $26.0 \pm 0.6$ & 4.00 & 2.27 \\
\hline 50 & $48.2 \pm 2.7$ & -3.65 & 5.70 \\
\hline 100 & $100.4 \pm 5.9$ & 0.45 & 5.83 \\
\hline 200 & $199.0 \pm 8.4$ & -0.51 & 4.24 \\
\hline 400 & $405.8 \pm 23.7$ & 1.45 & 5.84 \\
\hline \multirow{2}{*}{$\begin{array}{l}\text { Nominal concentration } \\
(\mathrm{ng} / \mathrm{ml})\end{array}$} & \multicolumn{3}{|l|}{ Inter-day } \\
\hline & Measured concentration ( $\mathrm{ng} / \mathrm{ml}$ ) & Accuracy (RE \%) & Precision (RSD \%) \\
\hline 12.5 & $12.9 \pm 1.1$ & 3.07 & 8.36 \\
\hline 25 & $25.9 \pm 0.8$ & 3.64 & 2.91 \\
\hline 50 & $48.2 \pm 3.0$ & -3.65 & 6.17 \\
\hline 100 & $98.1 \pm 7.2$ & -1.94 & 7.34 \\
\hline 200 & $199.7 \pm 7.6$ & -0.17 & 3.83 \\
\hline 400 & $414.6 \pm 21.9$ & 3.64 & 5.28 \\
\hline
\end{tabular}

Each data represents the mean \pm SD $(n=5)$., RE: relative error., RSD: relative standard deviation.

\section{Application to pharmacokinetic analysis}

The analytical method in this study was applied to the determination of nintedanib concentrations and calculation of pharmacokinetic parameters. The time courses of the nintedanib concentrations in plasma following intravenous administration in rats are shown in fig. 3. The pharmacokinetic parameters calculated by noncompartmental analysis are shown in table 2 . 


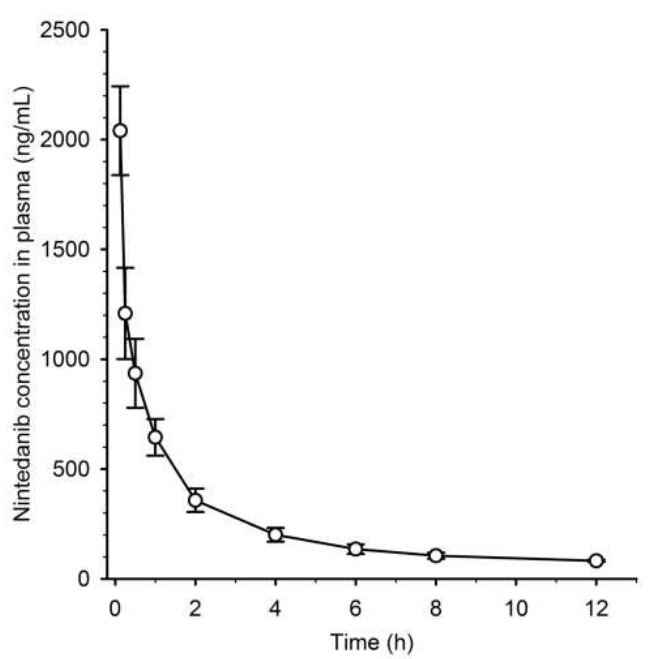

Fig. 3: Time profile of nintedanib in rat plasma after intravenous administration. Nintedanib $(20 \mathrm{mg} / \mathrm{kg} \mathrm{wt})$ was administered intravenously to rats. At each time point ( $7.5 \mathrm{~min}, 15 \mathrm{~min}, 30 \mathrm{~min}, 1 \mathrm{~h}, 2 \mathrm{~h}, 4 \mathrm{~h}, 6 \mathrm{~h}, 8 \mathrm{~h}$, and $12 \mathrm{~h}$ ) after administration, plasma was collected, and the nintedanib concentrations in each sample were determined. Each data represents the mean $\pm \operatorname{SD}(n=4)$

Table 2: Pharmacokinetic parameters of nintedanib in plasma after intravenous administration to rats

\begin{tabular}{lc}
\hline Pharmacokinetic parameter & \\
\hline $\mathrm{AUC}_{0-\infty}\left(\mathrm{ng}^{*} \mathrm{~h} / \mathrm{ml}\right)$ & $3921 \pm 293$ \\
$\mathrm{MRT}_{0-\infty}(\mathrm{h})$ & $5.84 \pm 0.40$ \\
$\mathrm{k}_{\mathrm{el}}\left(\mathrm{h}^{-1}\right)$ & $0.119 \pm 0.014$ \\
$\mathrm{~T}_{1 / 2}(\mathrm{~h})$ & $5.91 \pm 0.67$ \\
$\mathrm{Vd}$ & \\
$\mathrm{CL}(\mathrm{l} / \mathrm{hg})$ & $41.8 \pm 5.4$ \\
\hline
\end{tabular}

Each pharmacokinetic parameter was calculated from the data shown in fig. 3., The values represent the mean $\pm S D(n=4)$.

\section{DISCUSSION}

In this study, we described a rapid, simple, and sensitive HPLC-UV method to the determination of nintedanib in rat plasma. Nintedanib levels in plasma detected by HPLC-UV have been previously reported by Purnachand et al. [12]. However, our method was able to simultaneously detect nintedanib and its main metabolite (BIBF1202) (fig. 2). Furthermore, we improved the lower limit of quantification of HPLC-UV by this method. The value of the lower limit of quantification by using the previous HPLC-UV method was 2 $\mu \mathrm{g} / \mathrm{ml}$, whereas its value by using this method was $12.5 \mathrm{ng} / \mathrm{ml}$ (table 1). This quantitative sensitivity is sufficient to determine nintedanib concentrations in plasma after oral administration of a clinical dosage to humans [7].

In some pharmacokinetic studies, nintedanib concentration in biological samples has been measured by liquid chromatography with tandem mass spectrometry $[9,13,15,16]$. Overall, a bioanalytical method such as LC-MS/MS possesses a smaller value for the lower limit of quantification than methods such as HPLC-UV. However, LC-MS/MS systems are expensive and not generally available.

Therefore, HPLC-UV systems are more commonly used across laboratories for drug analysis of biological samples. Additionally, this analytical method requires simpler chromatographic conditions, including the use of simple mobile phases with small percentages of organic solvent in the absence of gradient programs. Moreover, this method has an easier preparation step for plasma samples: plasma proteins are precipitated by the addition of acetonitrile, following which the supernatant is subjected to centrifugation.

Thus, we evaluated the pharmacokinetics of nintedanib in rats using this enhanced HPLC-UV method (fig. 3 and table 2). The $V_{d s s}$ value $(41.8 \mathrm{~L} / \mathrm{kg})$ indicated that nintedanib was distributed widely in several organs. According to the previous study by $\mathrm{Xu}$ et al. [17], nintedanib concentrations in various organs including the liver, spleen, lungs, kidneys, and thymus were higher than those in plasma after oral administration in rats, supporting our findings.

\section{CONCLUSION}

In this study, a rapid, sensitive, and simple HPLC-UV method for the quantitation of nintedanib in rat plasma were developed and validated. The method was shown to be accurate and precise and was successfully applied to a pharmacokinetic study.

\section{ACKNOWLEDGEMENT}

This work was supported by Grants-in-Aid (No. 15K19165) for Young Scientists (B) and Grants-in-Aid (No. 17H02178) for Scientific Research (B) provided by the Japan Society for the Promotion of Science.

\section{AUTHORS CONTRIBUTIONS}

Kohei Togami is corresponding author developed the design of the experiments and wrote the manuscript. Kenta Fukuda carried out the validation of the HPLC method and pharmacokinetic experiments in rats. Kotaro Yamaguchi carried out the HPLC data acquisition. Sumio Chono proofreaded of the manuscript. Hitoshi Tada carried out the pharmacokinetic analysis and data interpretation.

\section{CONFLICT OF INTERESTS}

The authors declare no conflict of interest

\section{REFERENCES}

1. Hilberg F, Roth GJ, Krssak M, Kautschitsch S, Sommergruber W, Tontsch-Grunt U, et al. BIBF 1120: triple angiokinase inhibitor 
with sustained receptor blockade and good antitumor efficacy. Cancer Res 2008;68:4774-82.

2. Hostettler KE, Zhong J, Papakonstantinou E, Karakiulakis G, Tamm M, Seidel P, et al. Anti-fibrotic effects of nintedanib in lung fibroblasts derived from patients with idiopathic pulmonary fibrosis. Respir Res 2014;15:157.

3. McCormack PL. Nintedanib: first global approval. Drugs 2015;75:129-39.

4. Mazzei ME, Richeldi L, Collard HR. Nintedanib in the treatment of idiopathic pulmonary fibrosis. Ther Adv Respir Dis 2015;9:121-9.

5. Yamamoto N, Horiike A, Fujisaka Y, Murakami H, Shimoyama $\mathrm{T}$, Yamada Y, et al. Phase I dose-finding and pharmacokinetic study of the oral epidermal growth factor receptor tyrosine kinase inhibitor Ro50-8231 (erlotinib) in Japanese patients with solid tumors. Cancer Chemother Pharmacol 2008; 61:489-96.

6. Nakamura Y, Sano K, Soda H, Takatani H, Fukuda M, Nagashima $\mathrm{S}$, et al. Pharmacokinetics of gefitinib predict antitumor activity for advanced non-small cell lung cancer. J Thorac Oncol 2010;5:1404-9.

7. Ogura T, Taniguchi H, Azuma A, Inoue Y, Kondoh Y, Hasegawa $\mathrm{Y}$, et al. Safety and pharmacokinetics of nintedanib and pirfenidone in idiopathic pulmonary fibrosis. Eur Respir J 2015;45:1382-92.

8. Xiang QF, Wang F, Su XD, Liang YJ, Zheng LS, Mi YJ, et al. Effect of BIBF 1120 on the reversal of ABCB1-mediated multidrug resistance. Cell Oncol (Dordr) 2011;34:33-44.

9. Lin D, Qiao LM, Zhang YN, Liu Y, Liu XS. Simultaneous determination of nintedanib and its metabolite by UPLCMS/MS in rat plasma and its application to a pharmacokinetic study. J Pharm Biomed Anal 2016;117:173-7.

10. Abdessadek M, Tadmori AE, Attari AE, Diarra M, Magoul R, Ajdi F, et al. a Simple HPLC-UV method for determination of metformin in human plasma and erythrocytes application to therapeutic drug monitoring. Int J Pharm Pharm Sci 2015;7:35-9.

11. Farooqui NA, Dey A, Singh GN, Easwari TS. Development and validation of HPLC method for quantitative estimation of nimbolide in bulk and pharmaceutical dosage form. Int J Pharm Pharm Sci 2014;6:432-7.

12. Purnachand D, Veerareddy A, Ramadevi B, Kameswarrao CVSL, Reddy GS, Madhusudhanreddy B. Development and validation of a simple and sensitive stability indicating RP-HPLC assay method for determination of Nintedanib and stress degradation studies. J Chem Pharm Res 2015;7:774-82.

13. Stopfer $\mathrm{P}$, Rathgen $\mathrm{K}$, Bischoff $\mathrm{D}$, Ludtke $\mathrm{S}$, Marzin K, Kaiser R, et al. Pharmacokinetics and metabolism of BIBF 1120 after oral dosing to healthy male volunteers. Xenobiotica 2011;41:297-311.

14. Raghu G, Rochwerg B, Zhang Y, Garcia CA, Azuma A, Behr J, et al. An official ATS/ERS/JRS/ALAT clinical practice guideline: treatment of idiopathic pulmonary fibrosis. An Update of the 2011 Clinical Practice Guideline. Am J Respir Crit Care Med 2015;192:e3-19.

15. Eisen T, Shparyk Y, Macleod N, Jones R, Wallenstein G, Temple $\mathrm{G}$, et al. Effect of small angiokinase inhibitor nintedanib (BIBF 1120 ) on QT interval in patients with previously untreated, advanced renal cell cancer in an open-label, phase II study. Invest. New Drugs 2013;31:1283-93.

16. Kropff M, Kienast J, Bisping G, Berdel WE, Gaschler-Markefski B, Stopfer P, et al. An open-label dose-escalation study of BIBF 1120 in patients with relapsed or refractory multiple myeloma. Anticancer Res 2009;29:4233-8.

17. Xu XW, Su XJ, Zhang YN, Zheng XK, Lv PF, Hu J. Simultaneous determination of nintedanib and its metabolite BIBF 1202 in different tissues of mice by UPLC-MS/MS and its application in drug tissue distribution study. J Chromatogr B Analyt Technol Biomed Life Sci 2015;1002:239-44. 